\title{
Chimney stent deployment to overcome an acute right coronary occlusion due to a small right coronary sinus during transcatheter aortic valve implantation procedure
}

\author{
Mario García Gómez® ${ }^{\circledR}$, Sandra Santos Martínez® ${ }^{\circledR}$, Ana Serrador Frutos, \\ Tania Rodríguez Gabella, Ignacio J. Amat Santos \\ Servicio de Cardiología, Instituto de Ciencias del Corazón (ICICOR), Hospital Clínico Universitario, \\ CIBER de Enfermedades Cardiovasculares, Valladolid, Spain
}

An 84-year-old woman with degenerative aortic stenosis was admitted for planned transcatheter aortic valve replacement procedure. The baseline tomography showed the following measurements: aortic annulus (maximum, minimum, and mean diameters of $22.5,17.8$, and $20.2 \mathrm{~mm}$, respectively, perimeter $64.8 \mathrm{~mm}$, area $322 \mathrm{~mm}^{2}$ ), the Agatston score was 1300 , sinuses of Valsalva (left $27.7 \mathrm{~mm}$, right $23.8 \mathrm{~mm}$, noncoronary $28.1 \mathrm{~mm}$ ) (Fig. 1A). Likewise, an unusual takeoff of the right coronary artery (RCA) was encountered, without a clear definition within a small right coronary sinus (Fig. 1B); the height of left coronary ostia was normal (Fig. 1C). Based on previous measurements, a $23 \mathrm{~mm}$ Portico bioprosthesis was selected. After predilatation using an $18 \mathrm{~mm}$ true dilatation balloon, the patency of RCA was checked with the balloon inflated. Subsequently, the prosthesis was deployed and the patient started with signs of hemodynamic instability. Then, an RCA occlusion was found in a control angiography (Fig. 1D). Therefore, it was decided to remove the prosthesis, reassess the RCA patency (Fig. 1E) and position an undeployed $4 \times 30 \mathrm{~mm}$ Onyx stent at the RCA (Fig. 1F). Straightaway, the prosthesis was released and simultaneously the stent at the RCA was successfully deployed according to the "chimney stent" technique [1] (Fig. 1G). Finally, the proper position and expansion of the prosthesis, the absence of periprosthetic leak and the patency of the RCA were verified (Fig. 1H). Ultimately, the correct expansion of the stent was confirmed using intravascular ultrasound (Fig. 1I).

Conflict of interest: None declared

\section{References}

1. Gonzálvez-García A, Hernández-Matamoros H, Jurado-Román A, et al. Valve in valve procedure and left main stent: To deliver or not to deliver. Cardiol J. 2020; 27(1): 87-88, doi: 10.5603/ /CJ.2020.0018, indexed in Pubmed: 32103481.

Address for correspondence: Ignacio J. Amat Santos, MD, PhD, FESC, Instituto de Ciencias del Corazón (ICICOR), Hospital Clínico Universitario de Valladolid, Ramón y Cajal 3, 47005, Valladolid, Spain, tel: +34 9834200 26, fax: +34 983255305 , e-mail: ijamat@gmail.com

Received: 27.07.2020 Accepted: 29.07.2020

This article is available in open access under Creative Common Attribution-Non-Commercial-No Derivatives 4.0 International (CC BY-NC-ND 4.0) license, allowing to download articles and share them with others as long as they credit the authors and the publisher, but without permission to change them in any way or use them commercially. 


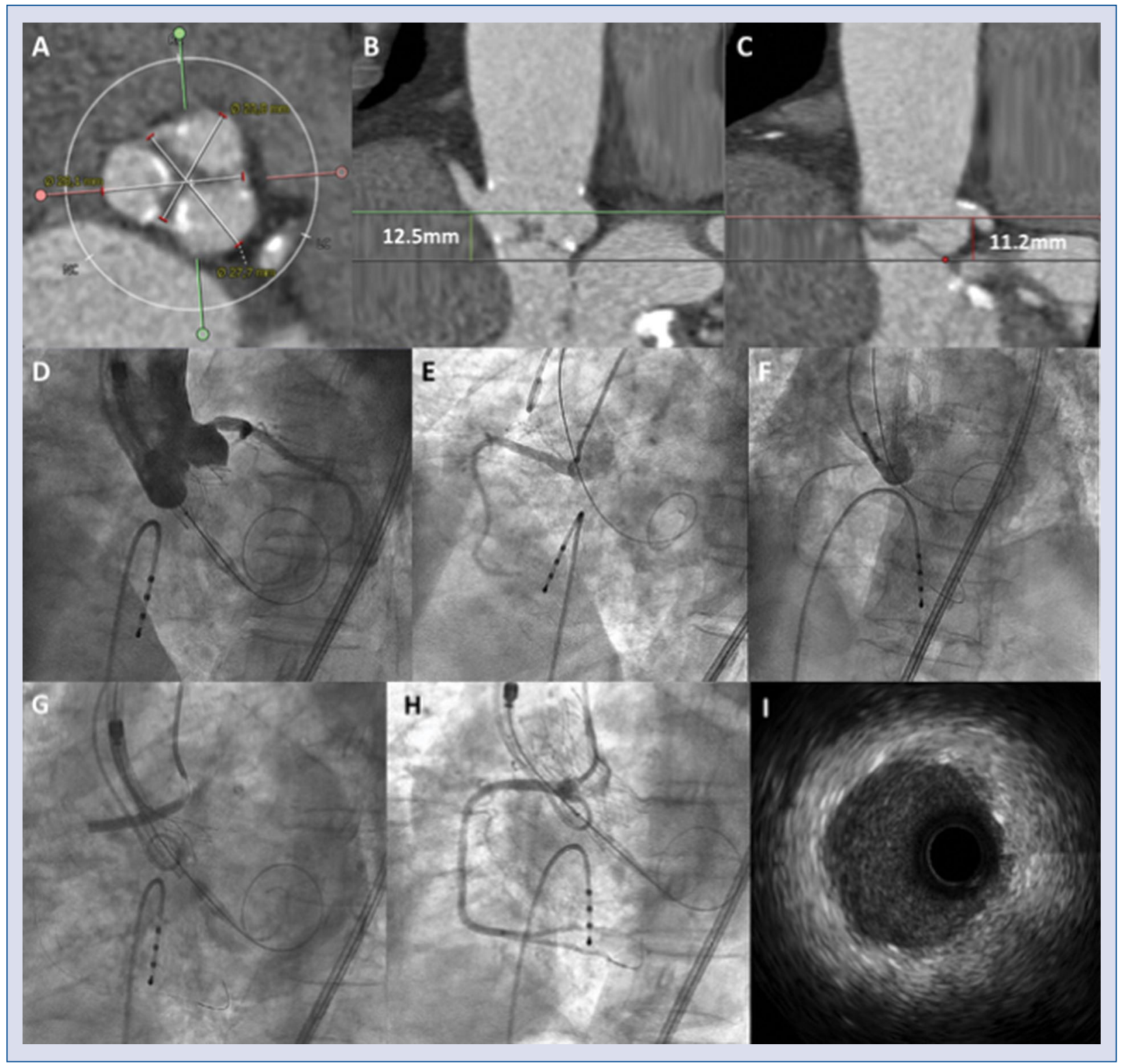

Figure 1. A. Tomographic image at the level of sinuses of Valsalva showing its measurements (left $27.7 \mathrm{~mm}$, right $23.8 \mathrm{~mm}$, noncoronary $28.1 \mathrm{~mm}$ ); B. Tomographic image showing lack of a clear definition of the origin of the right coronary artery (RCA) within a small right coronary sinus; C. Tomographic image showing a normal origin of the left main coronary artery; D. Angiographic image performed after deployment of the prosthesis showing acute occlusion of the RCA; E. Angiographic image performed after the prosthesis was recaptured showing patency of the RCA; F. Angiographic image showing the guidewire and progress of a stent in the RCA; G. Angiographic image showing the release of the prosthesis and implantation of the stent with the "chimney stent" technique in the RCA; H. Final aortography showing the proper position and expansion of the prosthesis, absence of periprosthetic leak and patency of the RCA; I. Intracoronary imaging using intravascular ultrasound showing correct expansion of the stent implanted in the RCA. 